\author{
Extended A bstract \\ for \\ $36^{\text {th }}$ AIAA Thermophysics Conference \\ Orlando, Florida, June 2003
}

\title{
Graphite Ablation and Thermal Response Simulation Under Arc-jet Flow Conditions
}

\author{
Y.-K. Chen, F. S. Milos, D. C. Reda, and D. A. Stewart \\ NASA Ames Research Center \\ Moffett Field, CA 94035-1000
}

\begin{abstract}
The Two-dimensional Implicit Thermal Response and Ablation program, TITAN, was developed and integrated with a Navier-Stokes solver, GIANTS, for multidimensional ablation and shape change simulation of thermal protection systems in hypersonic flow environments. The governing, equations in both codes are discretized using the same finite-volume approximatior. with a general body-fitted coordinate system. Time-dependent solutions are achieved by an implicit time marching technique using Gauess-Siedel line relaxation with alternating sweeps.

As the first part of a code validation study, this paper compares TITAN-GIANTS predictions with thermal response and recession data obtained from arc-jet tests recently conducted in the Interaction Heating Facility (IHF) at NASA Ames Research Center. The test models are graphite sphere-cones. Graphite was selected as a test material to minimize the uncertainties from material properties. Recession and thermal response data were obtained from two separate arc-jet test series. The first series was at a heat flux where graphite ablation is mainly due to sub imation, and the second series was at a relatively low heat flux where recession is the result of diffusion-controlled oxidation. Ablation and thermal response solutions for both sets of conditions, as calculated by TITAN-GIANTS, are presented and discussed in detail. Predicted shape change and temperature histories generaily agree well with he data obtained from the arc-jet tests.
\end{abstract}

\section{Nomenclature}

$$
\begin{aligned}
\mathrm{A} & =\text { area, } \mathrm{m}^{2} \\
B^{\prime} & =\dot{m} / \rho_{c} u_{e} C_{m}, \text { dimensionless mass blowing rate } \\
\mathrm{B}_{\mathrm{a}} & =\text { pre-exponential constant in Eq. }(6), \mathrm{s}^{-1} \\
\mathrm{C}_{\mathrm{h}} & =\text { Stanton number for heat transfer } \\
\mathrm{C}_{\mathrm{m}} & =\text { Stanton number for mass transfer } \\
\mathrm{c}_{\mathrm{p}} & =\text { specific heat, } \mathrm{J} / \mathrm{kg}-\mathrm{K} \\
\mathrm{E} & =\text { total energy per unit volume, } \mathrm{J} / \mathrm{m}^{3} \\
\mathrm{E}_{\mathrm{a}} & =\text { activation energy in Eq.(6), } \mathrm{J} / \mathrm{kmol} \\
\mathrm{F} & =\text { radiation view factor in Eq.(11) } \\
\mathrm{h} & =\text { enthalpy, } \mathrm{J} / \mathrm{kg} \\
\bar{h} & =\text { enthalpy of the partial-pyrolyzed solid, defined in Eq.(4), } \mathrm{J} / \mathrm{kg}
\end{aligned}
$$




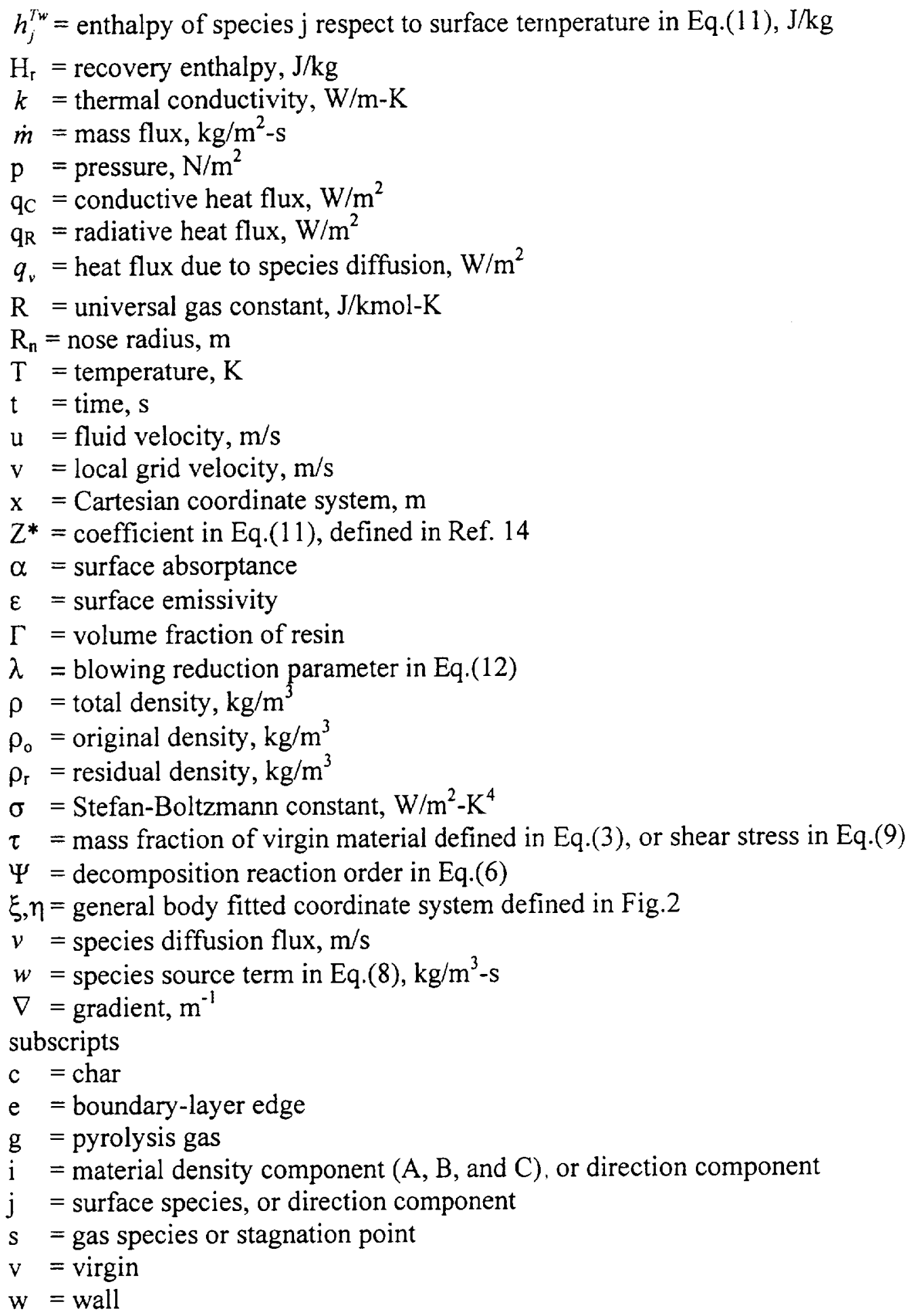

\section{Introduction}

Heatshields of spacecraft for planetary mission typically use thermal protection system (TPS) materials which pyrolyze and ablate at high temperature for mass-efficient $r$ e j e c t i o n o f aerothermal 
heat load. Pyrolysis is an internal decomposition of the solid which releases gaseous species, whereas ablation is a combination of processes which consume heatshield surface material. A reliable numerical procedure that can compute surface recession rate, mass loss, in-depth pyrolysis, and internal temperature time histories under general heating conditions is essential for the desigr and sizing of ablating spacecraft TPS materials.

The purpose of this paper is to compare TITAN-GIANTS predictions with arc-jet data and to study the accuracy of the simulation. Thermal response and recession data were obtained from arc-jet tests recently conducted in the Interaction Heating Facility (IHF) at NASA Ames Research Center. Graphite ablation and thermal properties have been widely studied, so graphite was selected as the test material to minimize the uncertainties from material properties (the accuracy of shape change and temperature history predictions can thus be better determired). However, the modeling of pyrolysis gas cannot be examined from graphite data. The pyrolysis gas effect will be studied in future work.

The recession and thermal response data studied here are from two separate arcjet test series. The first series was at relatively high heat flux in which graphite ablation was mainly due to sublimation, and the second series was at relatively low heat flux in which the recession was the result of diffusion-controlled oxidation. Typical $B^{\prime}$ vs. temperature curves for graphite in air at various surface pressures $(0.01,0.1$, and $1 \mathrm{~atm})$ are shown in Fig. 1. Above $3000 \mathrm{~K}, B^{\prime}$ is a strong function of temperature, and sublimation is the primary ablation process. At lower temperature, $B^{\prime}$ is relatively constant (approximately 0.175), and diffusion-controlled oxidation determines the ablation rate. At temperatures below $1100 \mathrm{~K}$, the ablation is kinetically controlled and is beyond the scope of this work.

\section{Background}

The Charring Material Thermal Response and Ablation Program ' (CMA) was developed by Aerotherm Corporation in the 1960s. This technique solved the onedimensional internal energy balance and decomposition equations coupled with the ablating surface energy balance condition to simulate the response of ablative heatshields in hypersonic flows. The Fully Implicit Ablation and Thermal Response program ${ }^{2}$ (FIAT) was developed at NASA Ames Research Center in the 1990s. Both FIAT and CMA solve the same governing equations. FIAT, which is numerically more stable, solves a wider range of problems compared with CMA, and has been used for TPS sizing calculations for various NASA space missions, such as Mars Pathfinder ${ }^{3}$ and Stardust. ${ }^{4}$

The Two-dimensional Implicit Thermal Response and Ablation (TITAN) program $^{5}$ was developed and coupled with the GIANTS (Gauss-Seidel implicit aerothermodynamic Navier-Stokes code with thermochemical surface boundary conditions) code $e^{6-9}$ using a loosely coupled method to perform high fidelity thermal response and shape change simulation for charring materials. The governing equations in both TITAN and GIANTS are discretized usirg the same finite-volume approximation with general body fitted coordinates. The scilution is achieved by an implicit time marching technique using Gauess-Siedel line relaxation with alternating sweeps. A fluidsolid coupled simulation is required to accurately predict shape change and aerothermal 
heating, because aerothermal heating distribu:ion is very sensitive to body shape, and shape change is a strong function of surface heating distribution. TITAN-GIANTS was also integrated with the commercial finite-elenent code, MARC, ${ }^{10}$ to perform thermal and structural analysis on the complex geometries of actual vehicles. "Details of TITAN's development and its formulation heve been discussed in a previous paper. ${ }^{5}$ Application of TITAN-GIANTS and TITAN-IMARC for full body heat-shield/structure analysis of a Mars sample return Earth Entry Vehicle and for simulation of a flat-faced cylinder arc-jet test model are demonstrated in Reference 11.

\section{Arc-Jet Facilities}

Arc-jet facilities are used to simulate the aerothermal heating environments experienced by space vehicles during atmospheric entry. The arc-jet tests discussed in this paper were conducted in the Ames $60 \mathrm{MW}$ Interaction Heating Facility. In the IHF, air is heated by the electric discharge in an 8-cm diameter, water-cooled constricted arc column. The hot gas is then expanded through a converging-diverging nozzle into an evacuated test chamber where the test model is located. The heat flux and pressure on the model surface can be varied by changing the electrical power input and the configuration of the nozzle, as well as the model location from the nozzle exit. The test model is mounted onto a mechanical swing arm and positioned between four and fourteen inches from the nozzle exit. The swing arm inserts the test model into the gas stream when the desired test conditions are reached, and then retracts the model from the stream after the desired exposure time has elapsed.

\section{Two-dimensional Implicit Thermal and Ablation Program - TITAN}

The ablating heat-shield material thermal response and shape change computations are performed using TITAN. The governing equations include energy conservation and a three-component decomposition model. The surface energy balance condition is solved with a moving grid to calculate the shape change due to surface recession. The internal energy balance is a transient thermal conduction equation with additional pyrolysis terms ${ }^{5}$

$$
\rho c_{p} \frac{\partial T}{\partial t}=\nabla \cdot(k \nabla T)-\left(h_{g}-\bar{h}\right) \nabla \cdot \dot{m}_{g}+\dot{m}_{g} \cdot \nabla k_{g}+v \rho c_{p} \nabla T
$$

The individual terms in Eq. 1 may be interpreted as follows: rate of storage of sensible energy, net rate of thermal conductive heat flux, pyrolysis energy-consumption rate, net rate of energy convected by pyrolysis, and convection rate of sensible energy due to coordinate system movement. The local specific heat is formulated from functions of temperature input for both virgin material and char. In partially pyrolyzed zones $\left(\rho_{c}<\rho<\right.$ $\rho_{v}$ ), the specific heat is obtained from the mixing rule

$$
c_{p}=\tau c_{p v}+(1-\tau) c_{p c},
$$

where $\tau$ is the mass fraction of virgin material in a mixture of virgin material and char: 
$\tau=\frac{1-\rho_{c} / \rho}{1-\rho_{c} / \rho_{v}}$

The thermal conductivity, $k$, is weighted in the same manner. The pyrolysis gas enthalpy, $h_{g}$, is an input function of temperature and pressure. The enthalpy of the partialpyrolyzed solid, $\bar{h}$, is defined as

$\bar{h}=\frac{\rho_{v} h_{v}-\rho_{c} h_{c}}{\rho_{v}-\rho_{c}}$.

A three-component decomposition model is used. The resin filler is assumed to consist of two components which decompose separately, while the reinforcing material is the third component which can decompose. The instantaneous density of the composite is given by:

$\rho=\Gamma\left(\rho_{A}+\rho_{B}\right)+(1-\Gamma) \rho_{c}$,

where $\mathrm{A}$ and $\mathrm{B}$ represent components of the resin, and $\mathrm{C}$ represents the reinforcing material. $\Gamma$ is the volume fraction of resin and is an input quantity. For graphite, the volume fraction, $\Gamma$, is 0 , and the reinforcing material density, $\rho_{c}$, is the graphite density. Each of the three components can decompose $b y$ the relation:

$\frac{\partial \rho_{i}}{\partial t}=-B_{a i} \exp \left(\frac{-E_{a i}}{R T}\right) \rho_{o i}\left(\frac{\rho_{i}-\rho_{r i}}{\rho_{o i}}\right)^{\psi_{i}}+\mathrm{v} \nabla \rho_{i}$,

where $\rho_{r i}$ is the residual or terminal density of component $i$, and $\rho_{o i}$ is the original density of component $i(i=\mathrm{A}, \mathrm{B}$, and $\mathrm{C})$. The motion of pyrolysis gas is assumed to be quasi-steady and one-dimensional (along the $\eta$ direction), and thus the mass flow rate of pyrolysis gas at the surface is calculated using the following approximation:

$\dot{m}_{g}=\frac{1}{A_{w}} \int_{0}^{\eta_{w}}-\left(\frac{\partial \rho}{\partial t}\right) A_{\eta} d \eta$.

The governing equations are discretized using a finite-volume approximation with a general body fitted coordinate system. The time-dependent solution is achieved by a implicit time marching technique using Gauess-Siedel line relaxation with alternating sweeps. If time accuracy is not of interest in the computation, the time step should be as large as possible, and the number of alternating, sweeps in each time step should be 1 . A time-accurate solution can be achieved by increasing the number of alternating sweeps in each time step or by reducing the time step. The computational grid is compressed during the course of computation to reflect the surface recession. Further details of the numerical procedures are presented in Reference 5. 


\section{Navier-Stokes equation solver - GIANTS}

To estimate the aerothermal heating distribution over a large angle blunt body, the hypersonic flow simulation is performed using the Navier-Stokes solver, GIANTS. The GIANTS code solves the time-dependent conservation equations of mass, momentum, and energy for the chemical and thermal non-zquilibrium flow-field. The species mass conservation equation is given by ${ }^{12}$

$$
\frac{\partial \rho_{s}}{\partial t}+\frac{\partial}{\partial x_{j}}\left(\rho_{s} u_{j}\right)=-\frac{\partial}{\partial x_{j}}\left(\rho_{s} v_{s j}\right)+w_{s}
$$

the total momentum conservation is written as

$$
\frac{\partial}{\partial t}\left(\rho u_{i}\right)+\frac{\partial}{\partial x_{j}}\left(\rho u_{i} u_{j}\right)=-\frac{\partial \tau_{i j}}{\partial x_{j}}
$$

and the total energy conservation as

$$
\frac{\partial E}{\partial t}+\frac{\partial}{\partial x_{j}}\left((E+p) u_{j}\right)=-\frac{\partial}{\partial x_{j}}\left(q_{j}+q_{v j}\right)-\frac{\partial}{\partial x_{j}}\left(u_{i} \tau_{i j}\right)-\sum_{s=1}^{n} \frac{\partial}{\partial x_{j}} v_{s j} h_{s} \text {. }
$$

The governing equations are discretized using the finite-volume method. The numerical method (fully implicit and Gauss-Seidel line relaxation) used to solve the discretized equations is exactly the same as that used in the TITAN code. This technique has been shown to yield steady-state results efficiently. A five species $\left(\mathrm{N}_{2}, \mathrm{O}_{2}, \mathrm{NO}, \mathrm{O}\right.$, and $\left.\mathrm{N}\right)$ gas model is used to accurately model the high temperature behavior of air. A bifurcation diffusion model ${ }^{13}$ was also implemented in this version of the code to correctly compute multi-species mass diffusion.

TITAN and GIANTS are interfaced through the surface energy balance boundary condition. The conditions at the ablating surface are determined by convective and radiative heating and by surface thermochemical interactions with the boundary layer gases. The surface energy balance equation employed is of the convective transfer coefficient type. This energy balance equation takes the following form ${ }^{1}$

$$
\begin{aligned}
& \rho_{e} u_{e} C_{h}\left(H_{r}-h_{e w}\right)+\rho_{e} u_{e} C_{m}\left[\sum\left(Z_{j e}^{*}-Z_{j w}^{*}\right) h_{j}^{T w}-B^{\prime} h_{w}\right]+\dot{m}_{c} h_{c}+\dot{m}_{g} h_{g} \\
& \quad+\alpha_{w} q_{R_{w}}-F \sigma \varepsilon T_{w}^{4}-q_{C w}=0
\end{aligned}
$$

The first term in Eq. 11 represents the sensible convective heat flux. The sum of the second, third, and fourth terms in Eq. 11 is defined as the total chemical energy at the surface. The $Z^{*}$ terms represent transport of chemical energy associated with chemical reactions at the wall and in the boundary layer. ${ }^{1 \cdot k}$ The $Z^{*}$ driving forces for diffusive mass transfer include the effects of unequal diffusion coefficients. The fifth and sixth terms are the radiative heat fluxes absorbed and re-radiated by the wall, respectively, and the last term, $\mathrm{q}_{\mathrm{C} w}$, represents the rate of conduction irto the material. The radiative heat flux, $q_{R w}$, such as radiation from a hot shock layer, is an input quantity. The prediction of shock layer radiation is not currently included in the coupled TITAN-GIANTS simulation. Here $B^{\prime}$ is the normalized mass blowing rate. The tables of $B^{\prime}$ for charring materials can be pre-generated using $A C E^{14}$ or $\mathrm{MAT}^{{ }_{15}}$ assuming chemical equilibrium.

The coupled TITAN-GIANTS simulation does not include surface mass blowing and ablation chemical species in the Navier-Stokes computation. Instead, a blowing 
correction parameter is introduced to account for the reduction in transfer coefficients due to the transpiration effect of the mass injection into the boundary layer. This approach was taken because previous studies of heat-ishield design for Mars Pathfinder ${ }^{3}$ and Stardust ${ }^{4}$, demonstrated that the computational time increased by about at least one order of magnitude if a blowing surface condition and ablation chemical species with their associated reactions were included in a flow sirnulation. In addition, the reaction rates of many gas phrase chemical reactions are unknown or not well studied. Thus, the prediction of Navier-Stokes solver becomes unreliable because of the uncertainties on the gas phrase chemical reaction rates. The introduction of a blowing reduction parameter can give a reasonable prediction for many ap olications and significantly cut the CPU time. The blowing rate correction for convective heat transfer is

$$
\frac{C_{h}}{C_{h 1}}=\frac{\ln \left(1+2 \lambda B^{\prime}\right)}{2 \lambda B^{\prime}}
$$

where $\lambda$ is the blowing reduction parameter, $C_{h}$ is the heat transfer coefficient for the ablating surface, and $C_{h l}$ is the heat transfer coefficient for a nonablating surface. When $\lambda=1 / 2$, Eq.(11) reduces to the classical lamincr-flow blowing correction. ${ }^{16}$

The computation starts with the TITAN code using initial estimates of surface heat flux and pressure without shape change as the surface boundary condition. At each time increment, TITAN obtains the in-depth thermal response solution based on current boundary conditions, and also calls the flow environment code to update the front-face energy balance boundary condition if necessary. The non-ablating surface heating and pressure are calculated by GIANTS, and a bloving reduction parameter of 0.5 is used in TITAN to take into account the laminar flow blockage due to surface mass blowing. When the maximum local surface recession exceeds a predefined criterion since the last surface convective heating was updated, a flow-field grid is generated based on the current body geometry, and then the flow simulation routine is called upon to compute the new aerothermal heating environment. Each call to the flow environment routine is a steady state calculation. As expected, the GIANTS calculation is much more computationally intensive than the thermal response computation performed by TITAN. For a TITAN-GIANTS coupled simulation, most of the CPU time is consumed by the flow environment calculation. Thus, the CPU t:me required for a simulation is primarily determined by the efficiency of the GIANTS code.

\section{Results and Discussion}

The first series of arc-jet tests were conducted with a stream enthalpy of 27 $\mathrm{MJ} / \mathrm{Kg}$, a stagnation point cold-wall heat flux of $2100 \mathrm{~W} / \mathrm{cm}^{2}$, and a stagnation point pressure of $0.75 \mathrm{~atm}$. The length of the heat pulse is $30 \mathrm{sec}$. The Poco graphite model is a $10^{\circ}$ half angle sphere-cone with nose radius of $1.905 \mathrm{~cm}\left(0.75^{\prime \prime}\right)$. The thermal properties of Poco graphite are from Ref. 17. The total length of the model is $8.89 \mathrm{~cm}(3.5$ "). The computational grids for both solid and fluid are shown in Fig. 2, where the solid grid is divided into two zones, and the fluid grid has a single zone. The first zone in the solid will be reconstructed as the recession exceeds preset criteria, and the second zone remains unchanged through the entire compstation. Surface heat flux and pressure 
distributions are recalculated using GIANTS when free stream conditions or the first zone in the solid grid is changed. The thermal response computation of the solid is transient, and the flow field is assumed to reach steady state instantaneously.

The heat flux distributions over the solid surface at $t=0$ and $30 \mathrm{sec}$ are shown in Fig. 3. The stagnation point heating rate at the $\epsilon$ nd of heat pulse $(t=30 \mathrm{sec})$ is about $90 \%$ of that at the beginning $(t=0 \mathrm{sec})$. However, the heating at $45^{\circ}$ from stagnation point becomes slightly higher toward the end of the heat pulse. Surface recession tends to blunt the spherical nose, and thus reduce stagnation point heating. Because of the uncertainties in estimated arc-jet free stream conditions and material surface conditions, the GIANTS solution at $\mathrm{t}=0$ does not exactly match the measured stagnation-point cold-wall heat flux $\left(2100 \mathrm{~W} / \mathrm{cm}^{2}\right)$. To account for these uncertainties, the normalized heat flux distributions from GIANTS were scaled to exactly match the measured initial stagnation point heat flux.

A comparison of predicted and measured surface recession is shown in Fig.4. The symbols for the graphite surface recession data are measured every 5 seconds at the stagnation point and at $45^{\circ}$ from the stagnation point. (Details of the measurements are described in Ref. 18.) The dark solid lines are the predicted recession using a coupled TITAN-GIANTS simulation. The total recession for this 30 -sec heat pulse at stagnation point is about $0.33 \mathrm{~cm}$ and at $45^{\circ}$ from stagnation point is about $0.165 \mathrm{~cm}$. The computation slightly over-predicts the recession at the stagnation point and slightly under-predicts the recession at $45^{\circ}$. The max mum difference between prediction and measurement is less than $10 \%$.

For comparison purposes, an additional FIAT computation was performed by assuming that the cold-wall heat flux was $2100 \mathrm{~W} / \mathrm{cm}^{2}$ and the thermal diffusion was one-dimensional. FIAT predicts much higher recession compared with TITAN at the stagnation point, as shown by the lighter solid line in Fig. 4. This result is not surprising, because the FIAT calculation does not take into account multidimensional heat conduction and shape change effects.

The $B^{\prime}$ histories at the stagnation point and at $45^{\circ}$ are presented in Fig. 5. In the first 2 seconds, the stagnation point is in the diffusion-controlled regime, but as the surface temperature increases the ablation enters the sublimation regime, and $B^{\prime}$ levels off near 0.4 until the end of heat pulse. At $45^{\circ}$ from the stagnation point, the surface remains in the diffusion controlled regime unti about 5 seconds, and then $B^{\prime}$ gradually increases to about 0.3 at $30 \mathrm{sec}$.

The predicted surface temperature his:ory at $45^{\circ}$ from the stagnation point is shown in Fig. 6 and compared with temperatıre measurements from an infrared (IR) camera and a pyrometer. At $t=30 \mathrm{sec}$, the predicted surface temperature is $3180^{\circ} \mathrm{C}$, the temperature measured from IR camera is $3030{ }^{\circ} \mathrm{C}$, and that from the pyrometer is 2940 ${ }^{\circ} \mathrm{C}$. The difference between the prediction and the IR is about $5 \%$ and between the prediction and the pyrometer is about $8 \%$. Further study is required to fully understand why the calculated temperature is higher than the measured data, and why the temperature reading from the IR camera is higher than that from the pyrometer.

There were no stagnation point surface temperature and in-depth temperature measurements in this test series. The predicted temperature contours of the graphite model at $t=30 \mathrm{sec}$ are presented in Fig. 7. The stagnation point temperature is above 
$3500 \mathrm{~K}$, and the back face of test model, which is connected to a water cooled holder, is assumed to remain at $312 \mathrm{~K}$. The dark solid line represents the initial surface contour. The area between the dark solid line and color contours is the material ablated during the $30 \mathrm{sec}$ heat pulse.

Figure 8 presents the flow field predictions at 0 and $30 \mathrm{sec}$. The upper half is the flow temperature contours at the beginning of test $(t=0 \mathrm{sec})$, and the lower half is that at the end of the heat pulse $(t=30 \mathrm{sec})$. The Knudsen number is about 0.023 . As expected, there is no significant change in flow pattern. The maximum fluid temperature around the shock is above $10,000 \mathrm{~K}$. The shock stand-off distance at $\mathrm{t}=30 \mathrm{sec}$ is slightly larger than at $t=0 \mathrm{sec}$. This is because ablation blunts the spherical section, and consequently reduces the heating in the stagnation region.

The second arc-jet test series was conducted with a stream enthalpy of $19 \mathrm{MJ} / \mathrm{Kg}$, a stagnation point cold wall heat flux of $593 \mathrm{~W} / \mathrm{cm}^{2}$, and a stagnation point pressure of $0.05 \mathrm{~atm}$. The duration of heat pulse was 60 se 2 . The ATJ graphite composite model is a $15^{\circ}$ half angle sphere-cone with nose radius of $0.95 \mathrm{~cm}\left(0.375^{\prime \prime}\right)$. The total length of model is $10.16 \mathrm{~cm}$ (4"). The material map and computational grids for both solid and fluid are shown in Fig. 9. The solid grid is again divided into two zones, and the fluid grid has a single zone. The first $3.81 \mathrm{~cm}(1.5 ")$ of the model is a mushroom-shaped piece of ATJ graphite. ${ }^{19}$ The rest of the model is built from a AETB 35/12 insulator with a small region of TUFROC to prevent overheatin: of the bond-line to the AETB.

The heat flux distributions over the soli.d surface at $t=0$ and $60 \mathrm{sec}$ are shown in Fig. 10. The stagnation point heating rate at the end of heat pulse $(t=60 \mathrm{sec})$ is about $95 \%$ of that at the beginning ( $\mathrm{t}=0 \mathrm{sec}$ ), and again (similar to the first series) at $45^{\circ}$ from stagnation point the heat flux becomes slightly higher at the end of heat pulse. However, the difference in surface heating between the beginning and the end of heat pulse is relatively small, compared with the first test series, because the total recession is lower in this second series of tests.

The stagnation point recession, measured at $t=25$ and $60 \mathrm{sec}$, is compared with predictions in Fig. 11. The solid line is the pred ction from TITAN, and the dashed line is from FIAT (a one-dimensional calculation with constant heat flux of $593 \mathrm{~W} / \mathrm{cm}^{2}$ ). As expected, FIAT predicts slightly higher recession compared with TITAN. The maximum difference between TITAN and FIAT is about $5 \%$ at $\mathrm{t}=60 \mathrm{sec}$. The measured stagnation point recessions at 25 and $60 \mathrm{sec}$ are 0.068 and $0.183 \mathrm{~cm}$, respectively. The predicted recession from TITAN at $25 \mathrm{sec}$ and $60 \mathrm{sec}$ is $0.071 \mathrm{~cm}$ and $0.174 \mathrm{~cm}$, respectively. The maximum difference between the TITAN prediction and the measurement is about $5 \%$. In this test series, graphite ablation is mainly due to diffusion-controlled oxidation. Thus, $B^{\prime}$ remains relatively constant (approximately 0.175 ) through the entire heat pulse. The total mass loss in this second test series is smaller than in the first one.

Three thermocouples (designated TC1, TC2, and TC3) are located on the model axis at depths of approximately $3.18,4.13$, and $6.67 \mathrm{~cm}$ from the initial stagnation point. The predicted temperature histories at these three locations from TITAN (dark solid lines) are presented and compared with the TC data in Fig. 12. Generally speaking, the TITAN predictions are in good agreement with he data. The TITAN predicted maximum temperatures of TC1 and TC2 are slightly below the data, but the predicted cooling rates for these two TC's are slightly lower than data. At the location of TC3, the TITAN prediction is slightly lower than the data most of the time. 
Surface temperature data are not arailable for this test series. Predicted temperature contours at $\mathrm{t}=60 \mathrm{sec}$ (end of the heat pulse) and at $200 \mathrm{sec}$ (during cooldown) are shown in Figs. 13 and 14, respertively. The peak temperature at $60 \mathrm{sec}$ is above $2700 \mathrm{~K}$ around stagnation point, and at $200 \mathrm{sec}$ the hottest location is about $1200 \mathrm{~K}$ near the interface between the graphite and the AETB. The back face of model is connected to a water cooled holder and assumed to be at $312 \mathrm{~K}$. The dark solid line again represents the initial surface contour.

Figure 15 presents the flowfield predict ons at 0 and $60 \mathrm{sec}$. The upper half is the temperature contours at the beginning of heat fulse $(\mathrm{t}=0 \mathrm{sec})$, and the lower half is that at the end of heat pulse $(t=60 \mathrm{sec})$. The Knudsen number for this case is about 0.1 . These results are similar to the first series (Fig.8) in that there is no significant change in flow pattern. The maximum fluid temperature around the shock is above $7000 \mathrm{~K}$. The shock stand-off distance at $\mathrm{t}=60 \mathrm{sec}$ is almost the same as that at $\mathrm{t}=0 \mathrm{sec}$.

\section{Conclusions}

Predictions from the integrated TITAN-GIANTS code were compared with thermal response and recession data obtained from arc-jet tests conducted in the Interaction Heating Facility at NASA Ames Research Center. The test models are graphite sphere-cones. The arc-jet data were tak en from two separate test series. The first test series $\left(q_{s}=2,100 \mathrm{~W} / \mathrm{cm}^{2}\right.$, and $P_{w}=0.75 \mathrm{~atm}$.) had graphite ablation in the sublimation regime, and the second test series $\left(q_{s}=593 \mathrm{~W} / \mathrm{cm}^{2}\right.$, and $\left.P_{w}=0.05 \mathrm{~atm}\right)$ had ablation in the diffusion controlled oxidation regime. Ablation and thermal response solutions calculated by TITAN-GIANTS for both sets of test conditions agree reasonably well with the measurements. The calculations slightly over-predict the surface temperature at $45^{\circ}$ from the stagnation point fo: the sublimation case, and slightly underpredict in-depth maximum temperatures for ciffusion-controlled case. The maximum difference in recession between TITAN predictions and measurement is less than $10 \%$. A one-dimensional FIAT computation can be used to roughly estimate the stagnation point recession, but not to predict in-depth thermal response.

\section{References}

'Anon., User's Manual: Aerotherm Charring Material Thermal Response and Ablation Program, Acurex Corporation, Aerotherm Division, Mountain View, California, Aug. 1987.

${ }^{2}$ Chen, Y.-K., and Milos, F.S., "Ablation and Thermal Analysis Program for Spacecraft Heatshield Analysis," J. of Spacecraft and Rockets, Vol. 36, No. 3, May-June 1999, pp. 475-483.

${ }^{3}$ Chen, Y.-K., Henline, W.D., and Tauber, M.E., "Mars Pathfinder Trajectory Based Heating and Ablation Calculations", J. of Spacesraft and Rockets, Vol. 32, No. 2, MarchApril. 1995, pp 225-230.

${ }^{4}$ Olynick, D.R., Chen, Y-K, and Tauber, M.E., "Aerothermodynamics of the Stardust Sample Return Capsule", J. of Spacecraft and Rockets, Vol. 36, No. 3, May-June 1999, pp. 442-462. 
${ }^{5}$ Chen, Y.-K., and Milos, F.S., "Two-Dimensional Implicit Ablation Thermal Response and Ablation Program for Charring Materials on Hypersonic Space Vehicles," AIAA Paper 2000-0206, January 2000.

${ }^{6}$ MacCormack, R.W., "Current Status of Numerical Solutions of the Navier-Stokes Equation," AIAA Paper 85-0032, Jan 1985.

7Candler, G.V., and MacCormack, R. W., "Hypersonic Flow Past 3-D Configuration," AIAA Paper 87-0480, June 1987.

${ }^{8}$ Candler, G.V., "The Computation of Hypersonic Ionized Flows in Chemical and Thermal Nonequilibrium," AIAA Paper 88-0511, January 1988.

${ }^{9}$ Chen, Y.-K., Henline, W.D., Stewart, D.A, and Candler, G.V., "Navier-Stokes Solutions with Surface Catalysis for Martian Atmospherical Entry," J. of Spacecraft and Rockets, Vol 30, No 1, Jan-Feb 1993, pp. 32-42.

${ }^{10}$ Anon., Users Manual, MARC Analysis Research Corporation, Volume A: Users Information, 1994, MARC Analysis Research Corporation, Palo Alto, CA.

${ }^{1 "}$ Chen, Y.-K., and Milos, F.S., "Thermal Response Modeling System for a Mars Sample Return Vehicle", The 12th Thermal and Fluids Analysis Workshop, Sept. 2001.

${ }^{12}$ Lee, J.H., "Basic Governing Equations for the Flight Regimes of Aeroassisted Orbital Transfer Vehicles", Thermal Design of Aeroassisted Orbital Transfer Vehicles, edited by H.F.Nelson, Vol. 96, Progress in Astronautics and Aeronautics, AIAA, New York, 1985, pp. 3-53.

${ }^{13}$ Moyer, C.B., and Rindal, R.A., "Finite Difference Solution for the In-Depth Response of Charring Materials Considering Surface Chemical and Energy Balances," Aerotherm Corporation, Mountain View, California, Final Report 66-7, Part II, March 1967 (also NASA CR-1061, June 1968).

${ }^{14}$ Anon., User's Manual: Aerotherm Chemical Equilibrium Computer Program, Acurex Corporation, Aerotherm Division, Mountain View, California, Aug. 1981.

${ }^{15}$ Milos, F.S., and Chen, Y.-K., "Comprehensive Model for Multi-Component Ablation Thermochemistry," AIAA Paper 97-0141, Jan. 1997.

${ }^{16}$ Kays, W.M., and Crawford, M.E., Convective Heat and Mass Transfer, 2nd Edition, McGraw-Hill, 1980, pp. 355-357.

${ }^{17}$ Private Communication (from Al Covington)

${ }^{18}$ Reda, D., To be published as NASA TM.

${ }^{19}$ Touloukian, Y. S., Powell, R. W., Ho, C. Y., and Klemens, P. G., Thermal Conductivity Nonmetallic Solid, Thermophysical Properties of Matter, Vol. 2, 1970, pp. 21-23. 


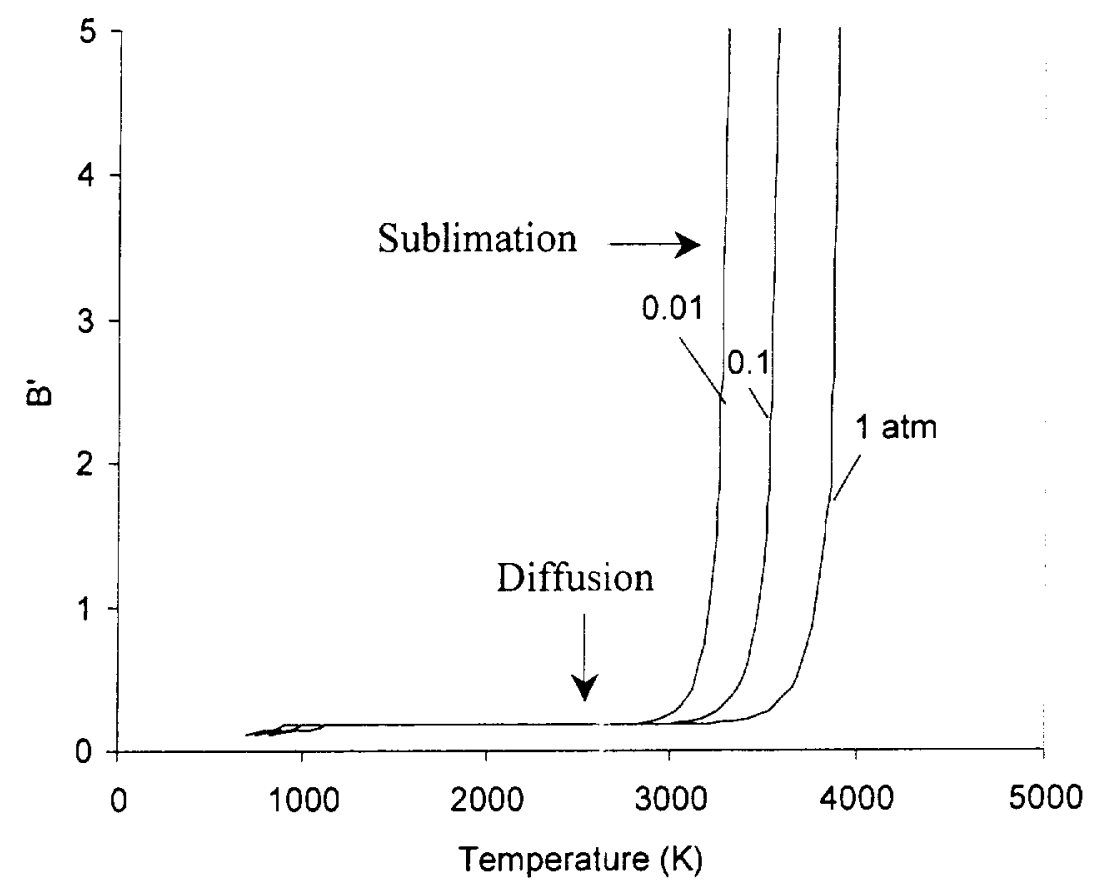

Figure 1: Graphite $B^{\prime}$ curves in ai: (generated using JANAF data)

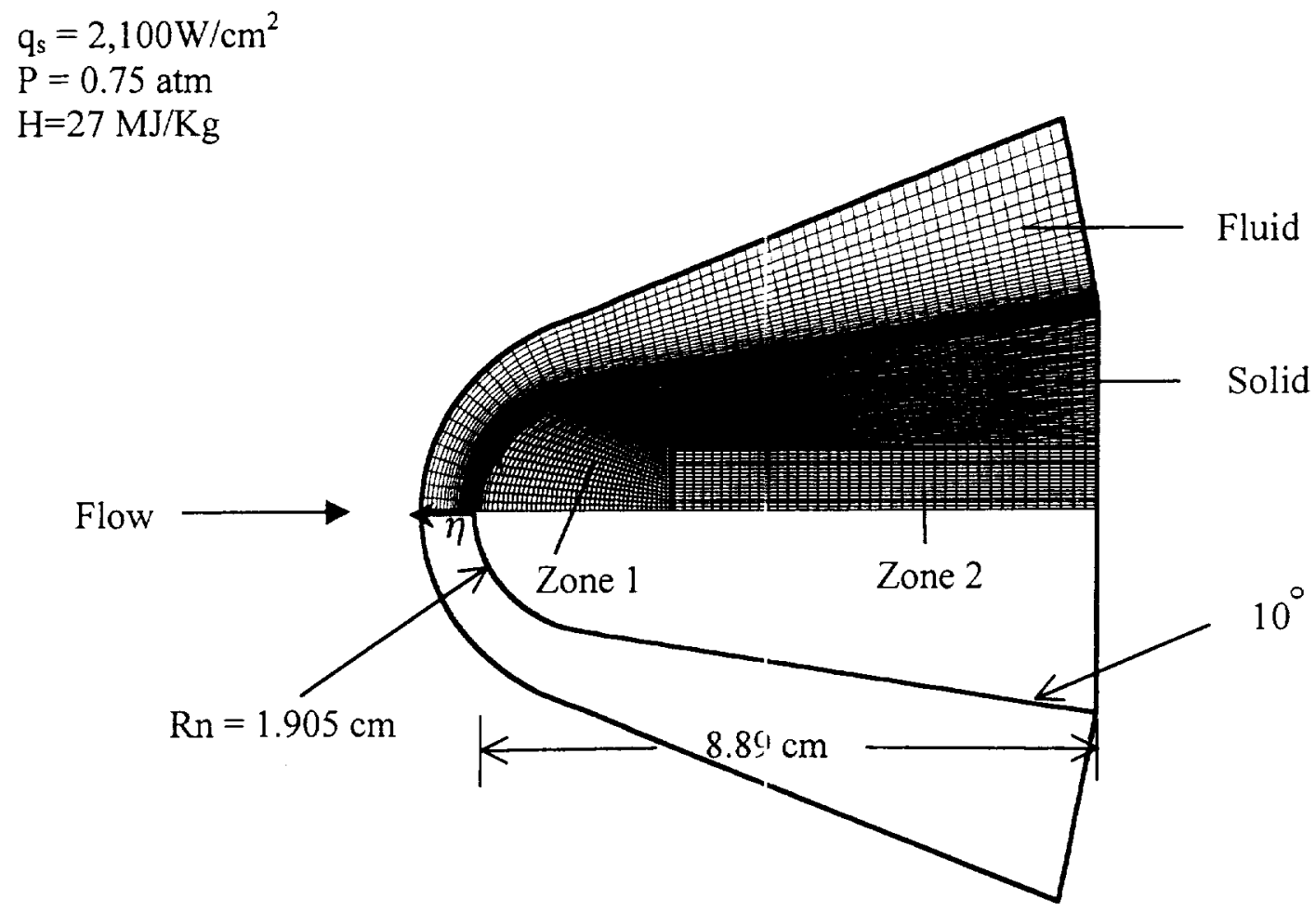

Figure 2: Computational grid for test series 1 


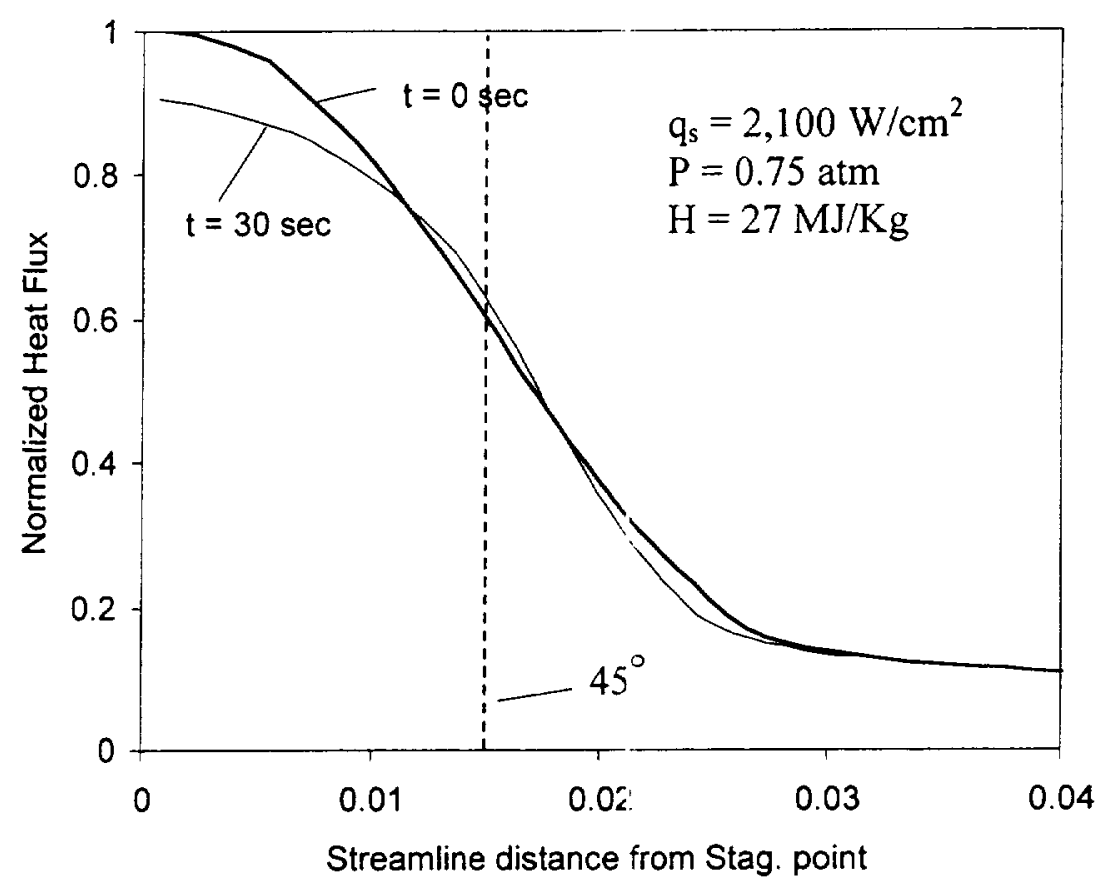

Figure 3: Heat flux distributions at $\mathrm{t}=0$ and $30 \mathrm{sec}$.

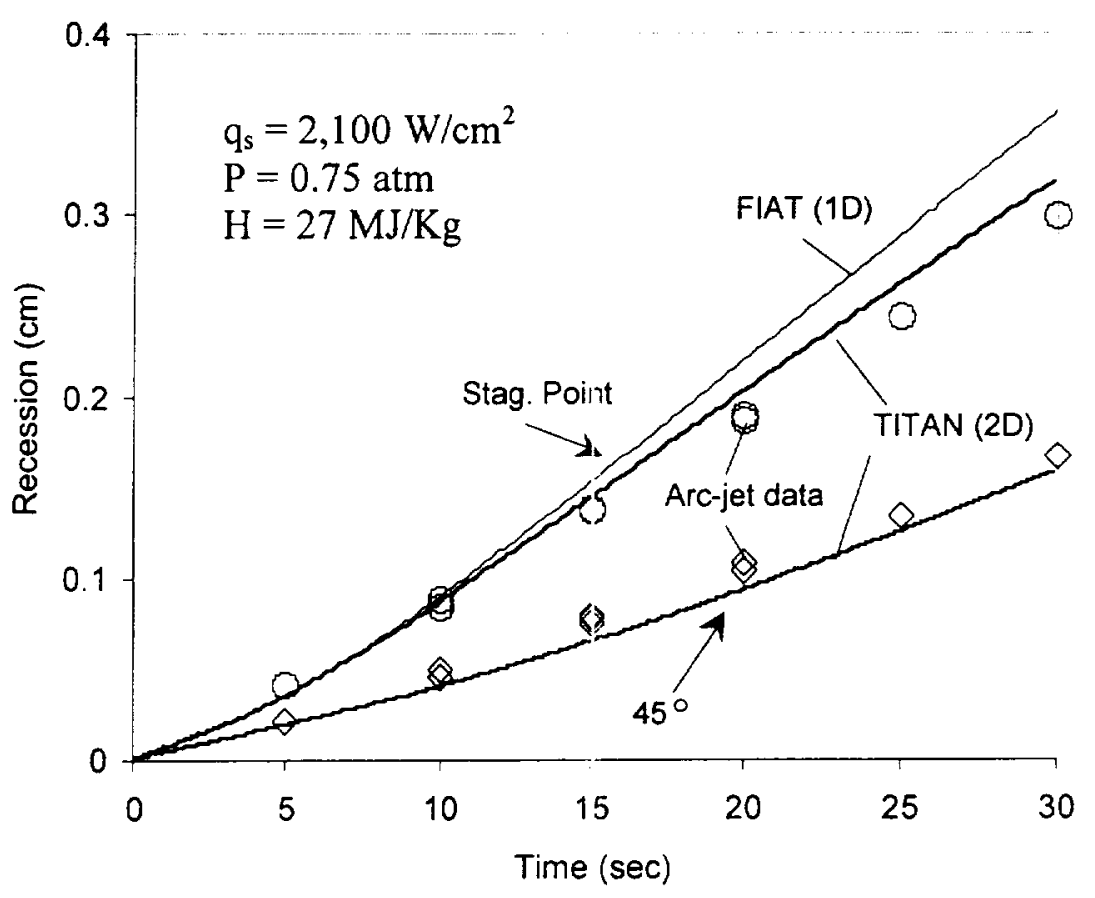

Figure 4: Computed and measured surface recessions 


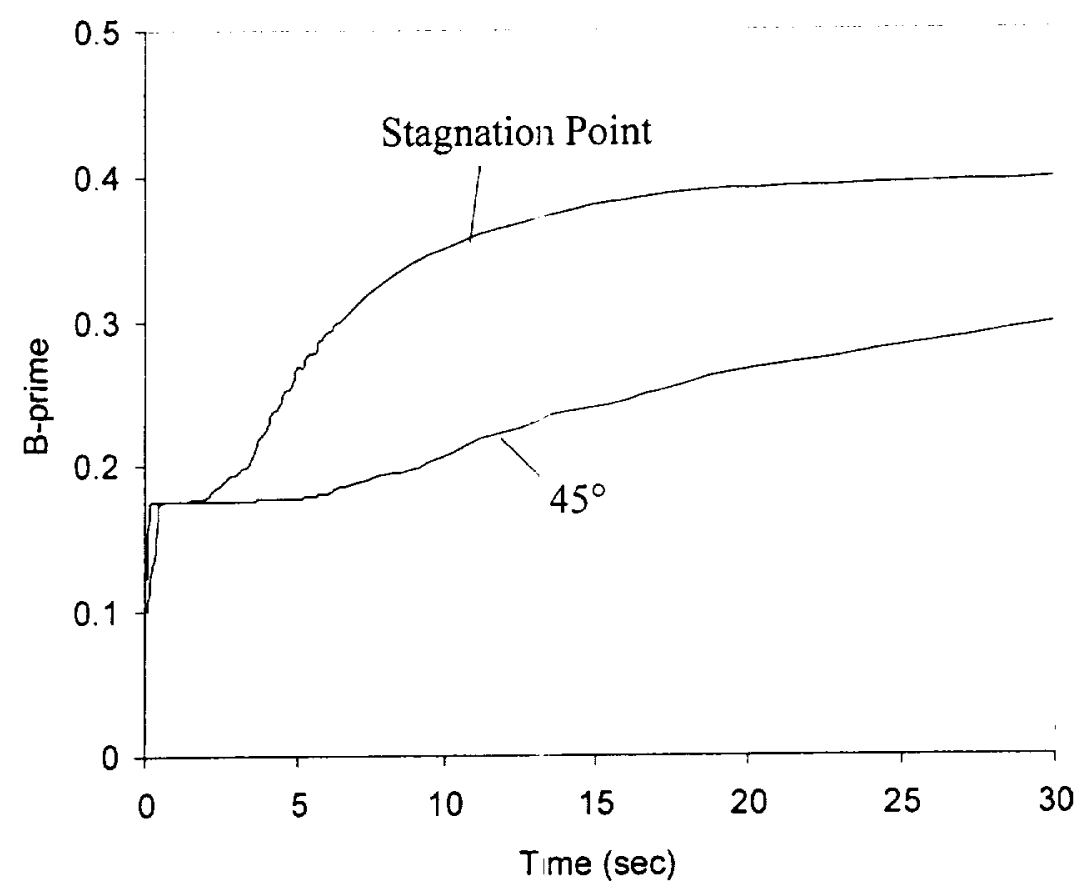

Figure 5: $B^{\prime}$ vs. tim $\approx$ at two surface locations

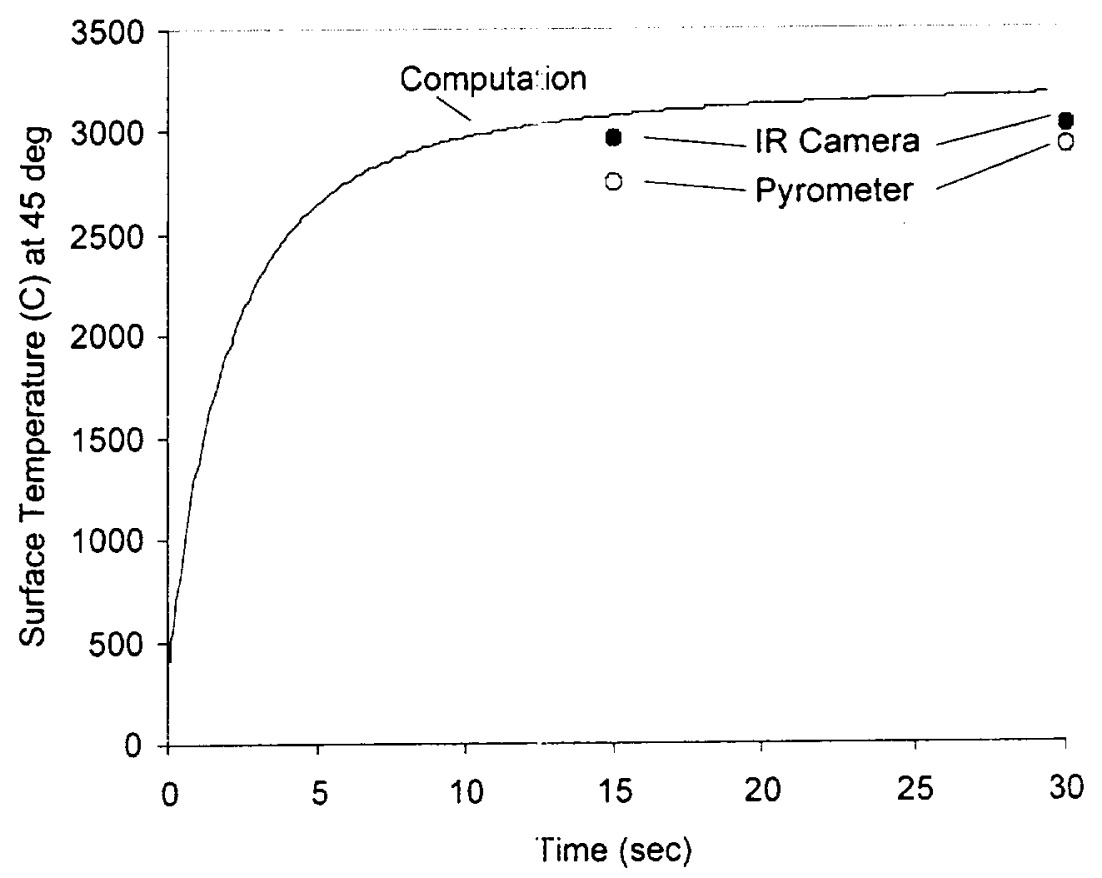

Figure 6: Surface temperature history at $45^{\circ}$ from Stagnation Point 


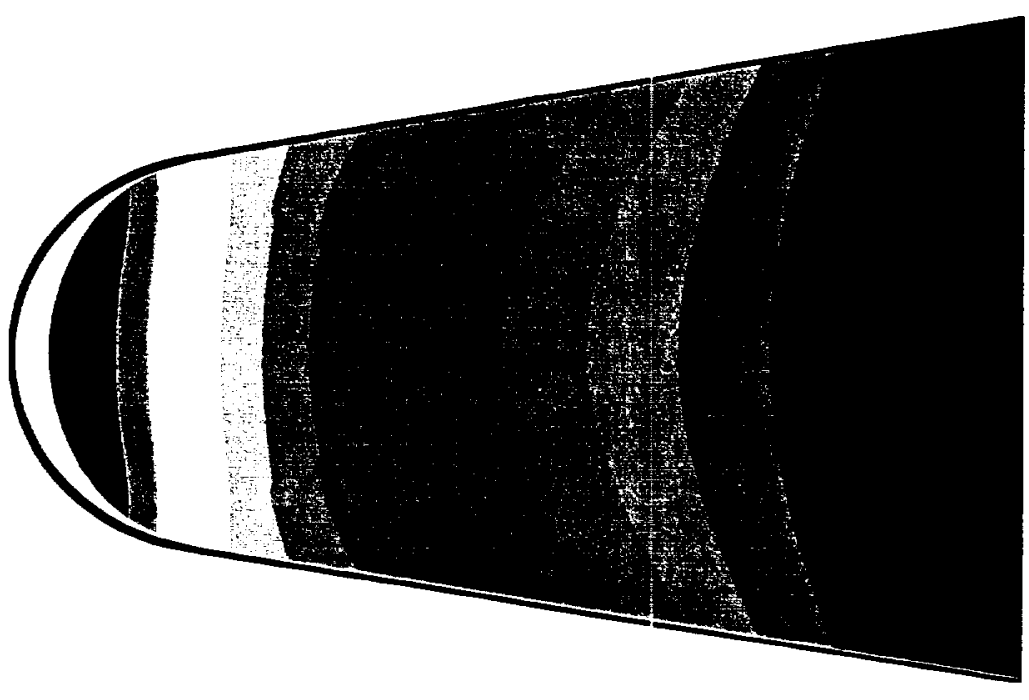

1686

1471

1257

1043

829

614

400

Figure 7: Temperature contours for graphite model at $\mathrm{t}=30 \mathrm{sec}$

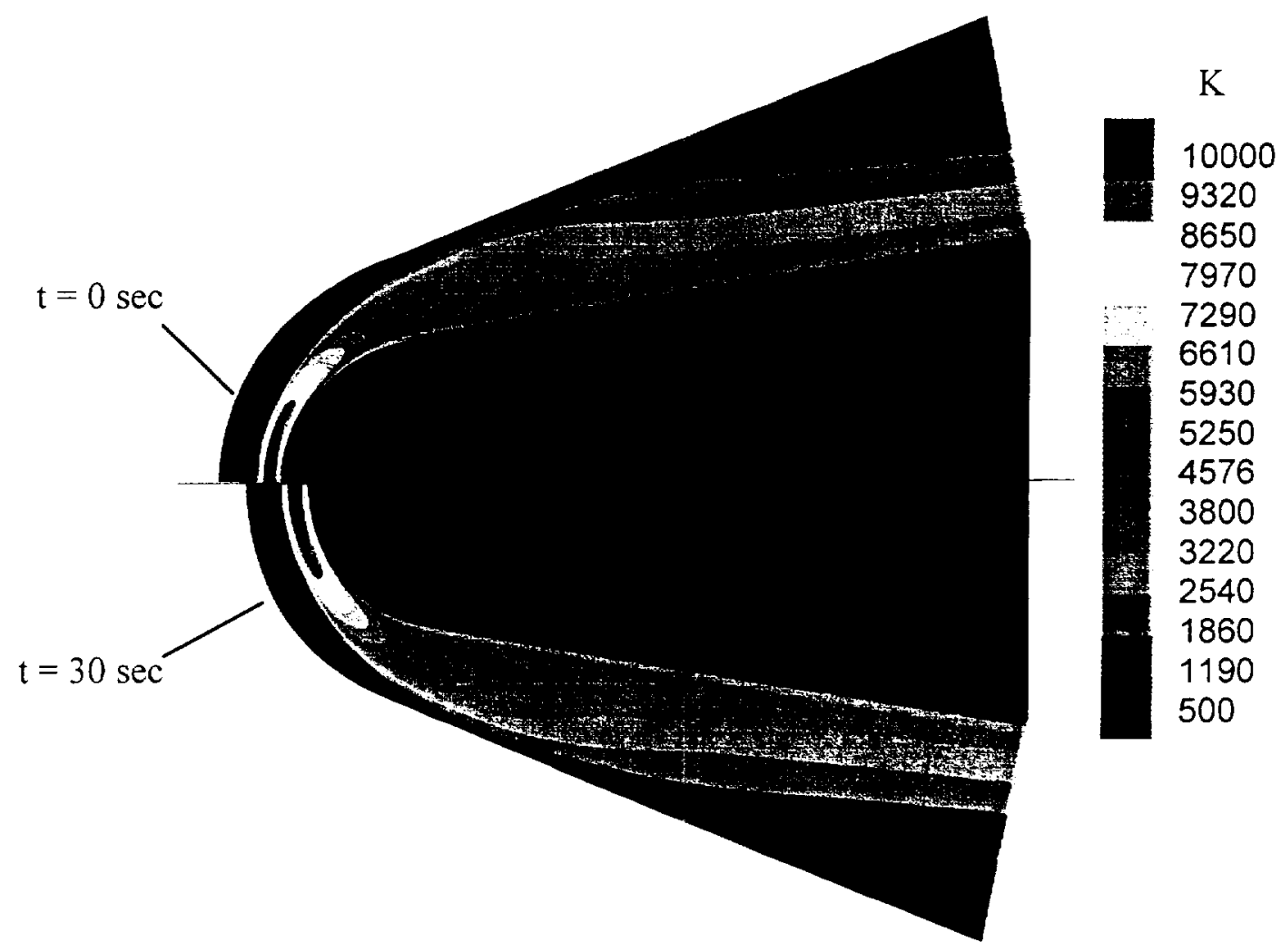

Figure 8: Flowfield temperature contours at $\mathrm{t}=0$ and $30 \mathrm{sec}$. 


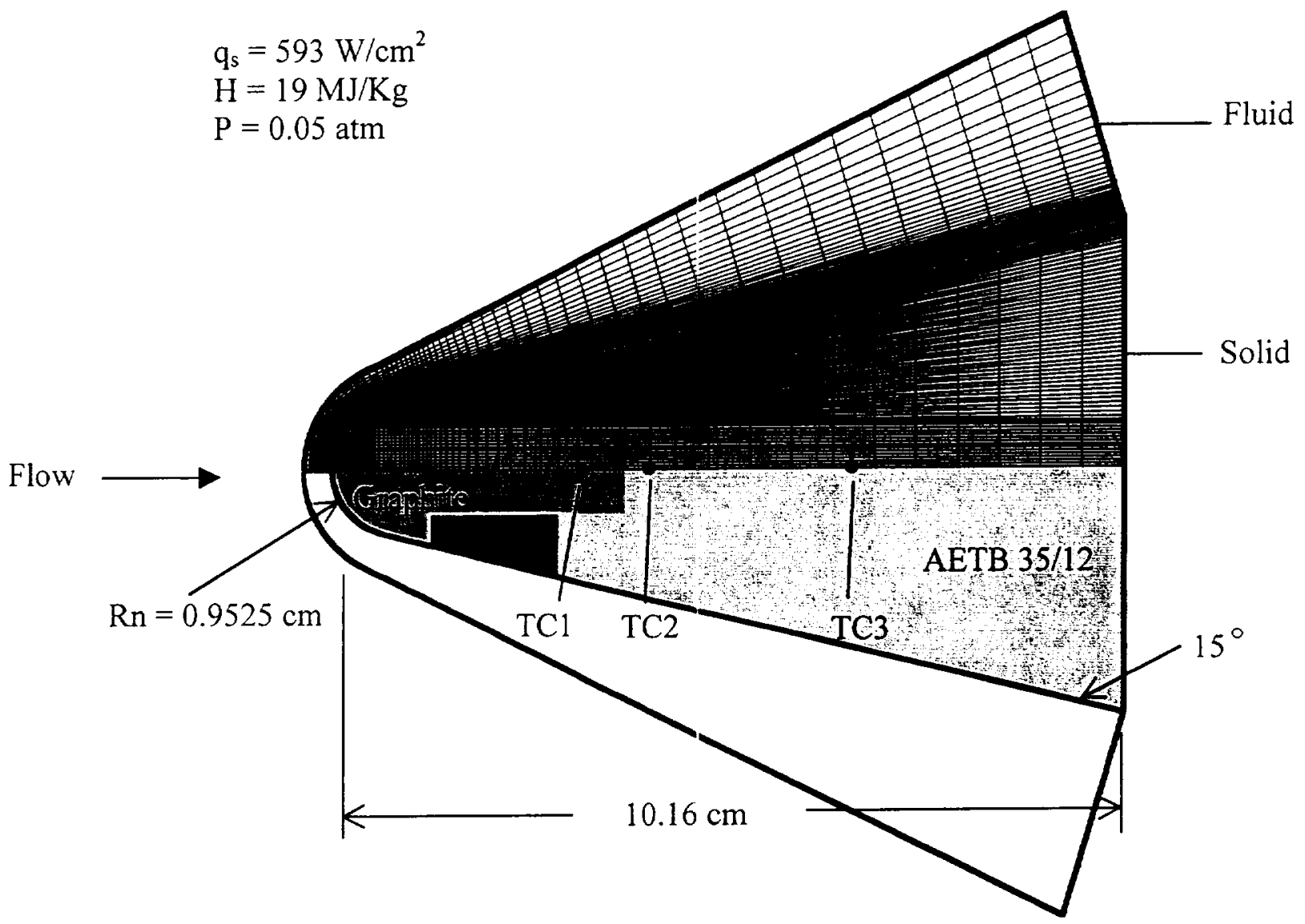

Figure 9: Comput ational grid for test series 2

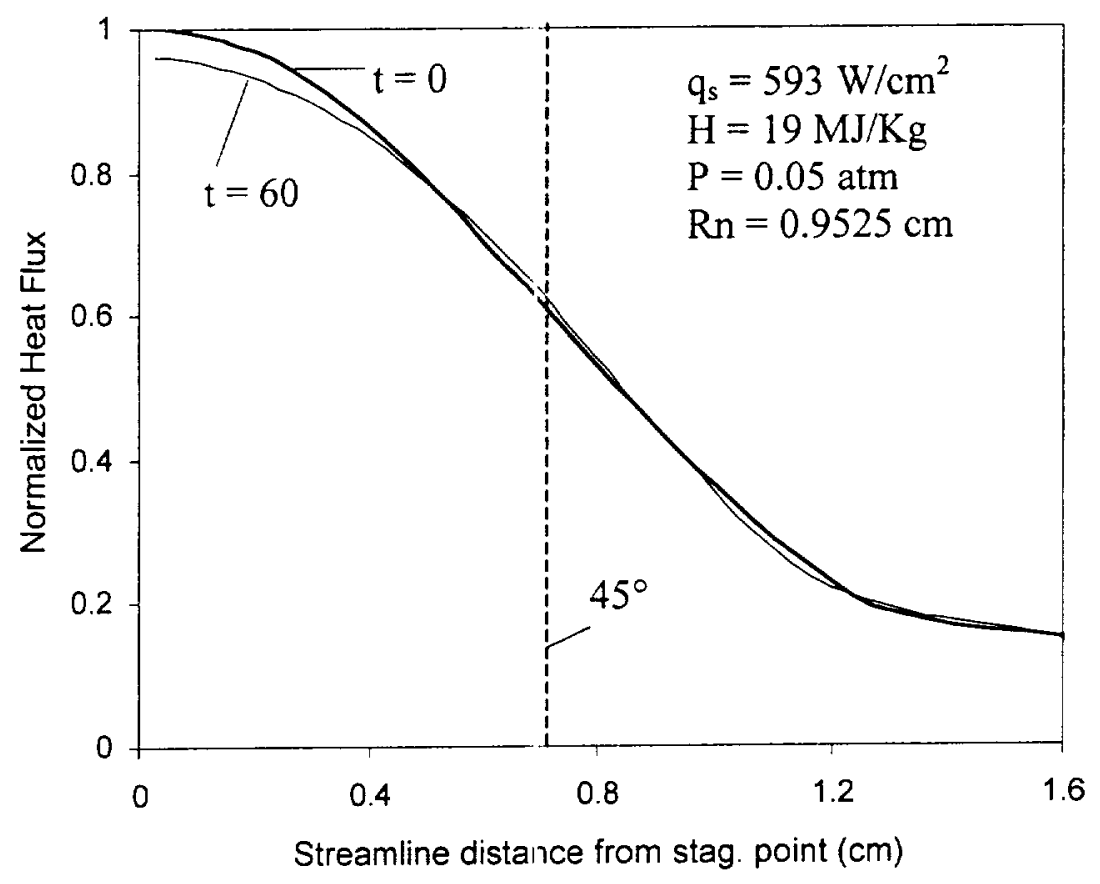

Figure 10: Heat flux distributions at $\mathrm{t}=0$ and $60 \mathrm{sec}$. 


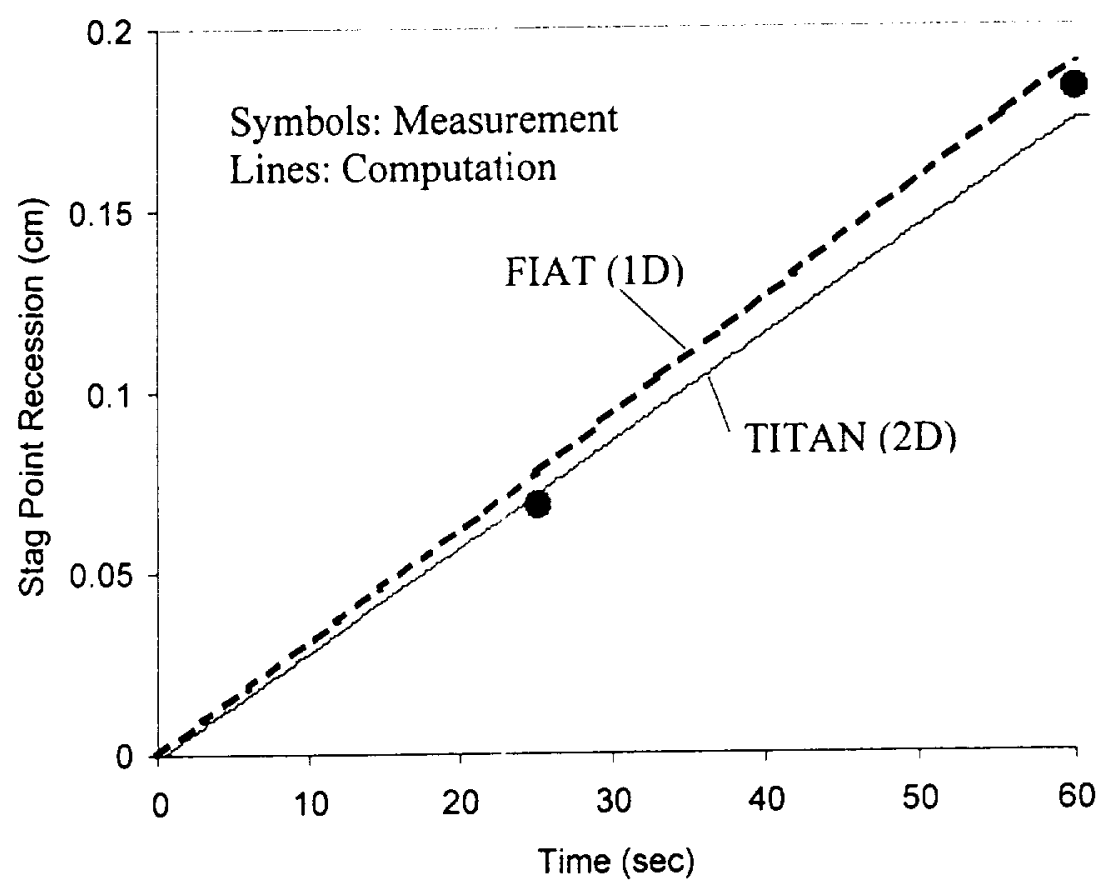

Figure 11: Computed and measured surface recessions

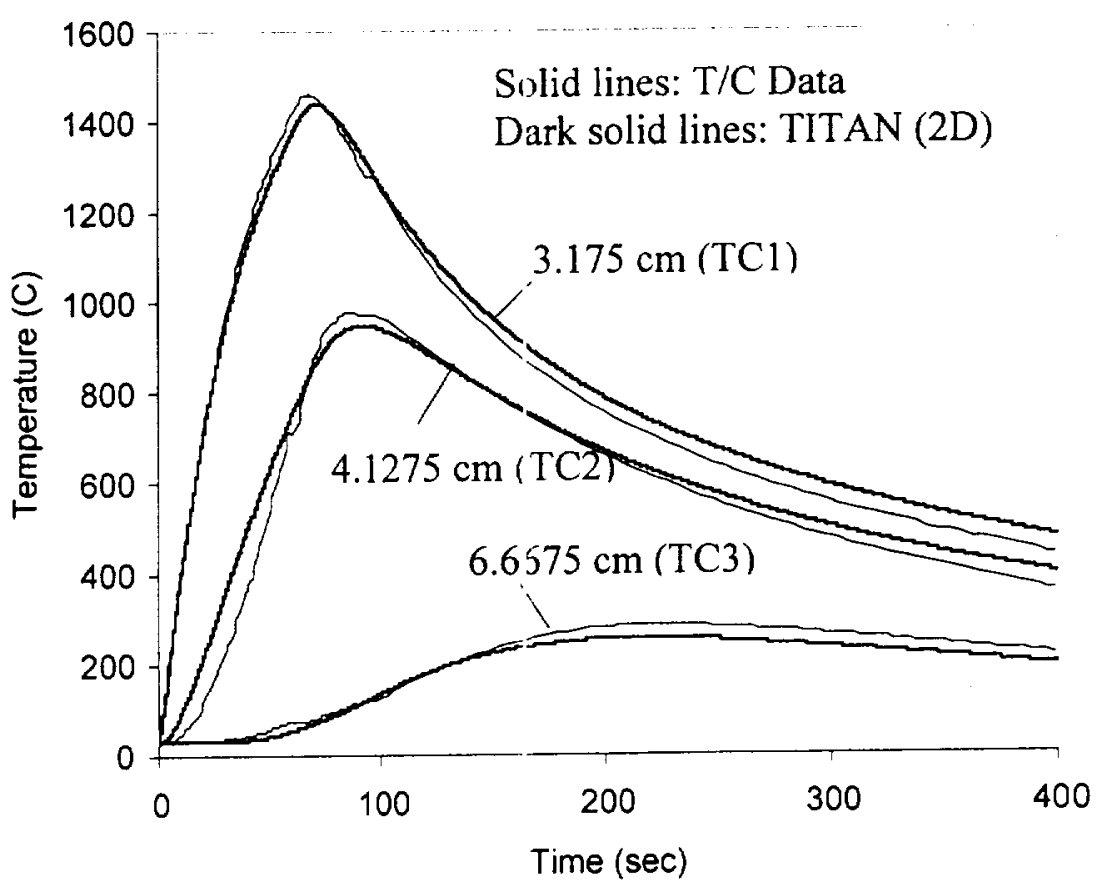

Figure 12: In-depth temperature histories along axis at three depths 


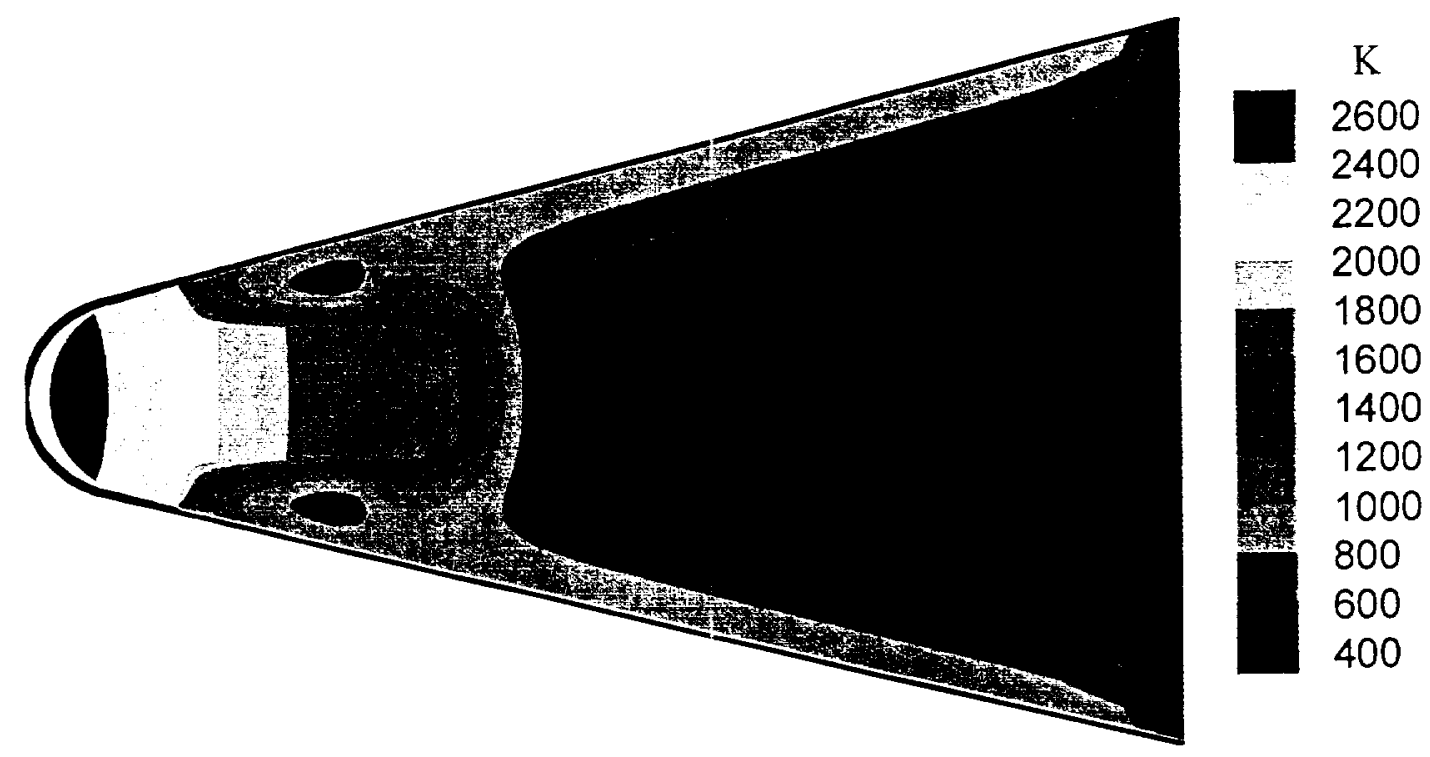

Figure 13: Temperature contours for composite model at $t=60 \mathrm{sec}$

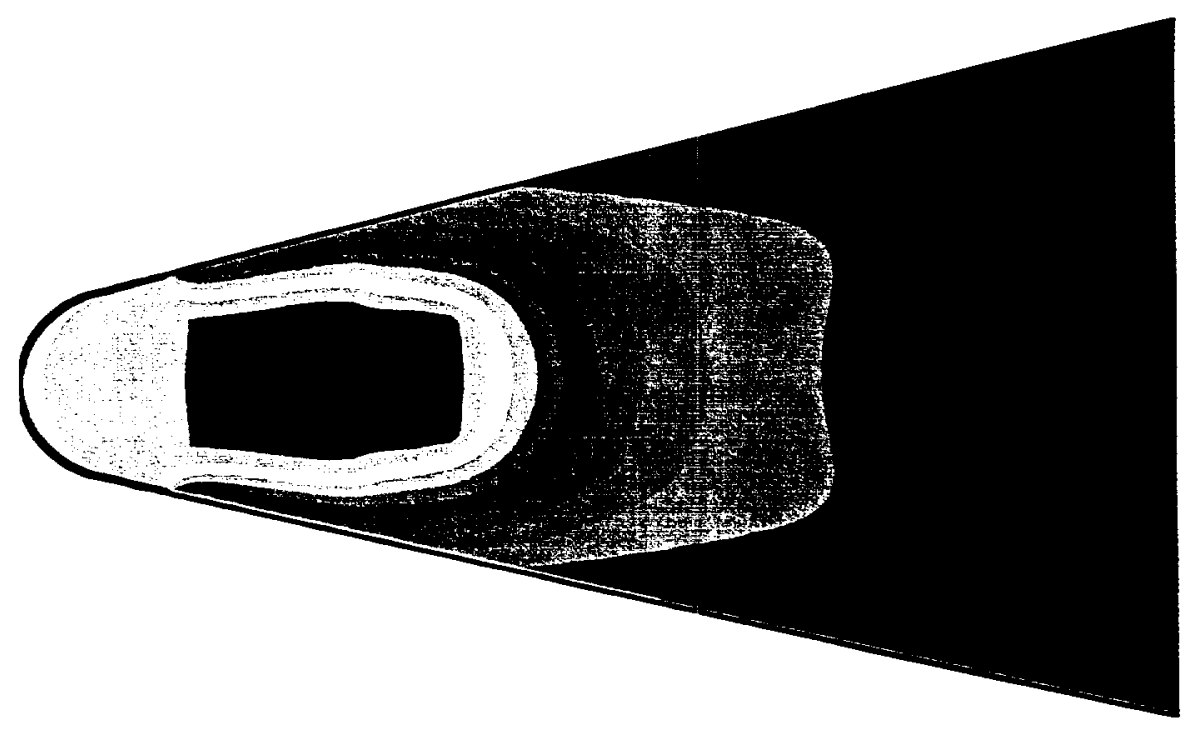

K

1100

1032

964

895

827

759

691

623

555

486

418

350

Figure 14: Temperature contours for composite model at $t=200 \mathrm{sec}$ 


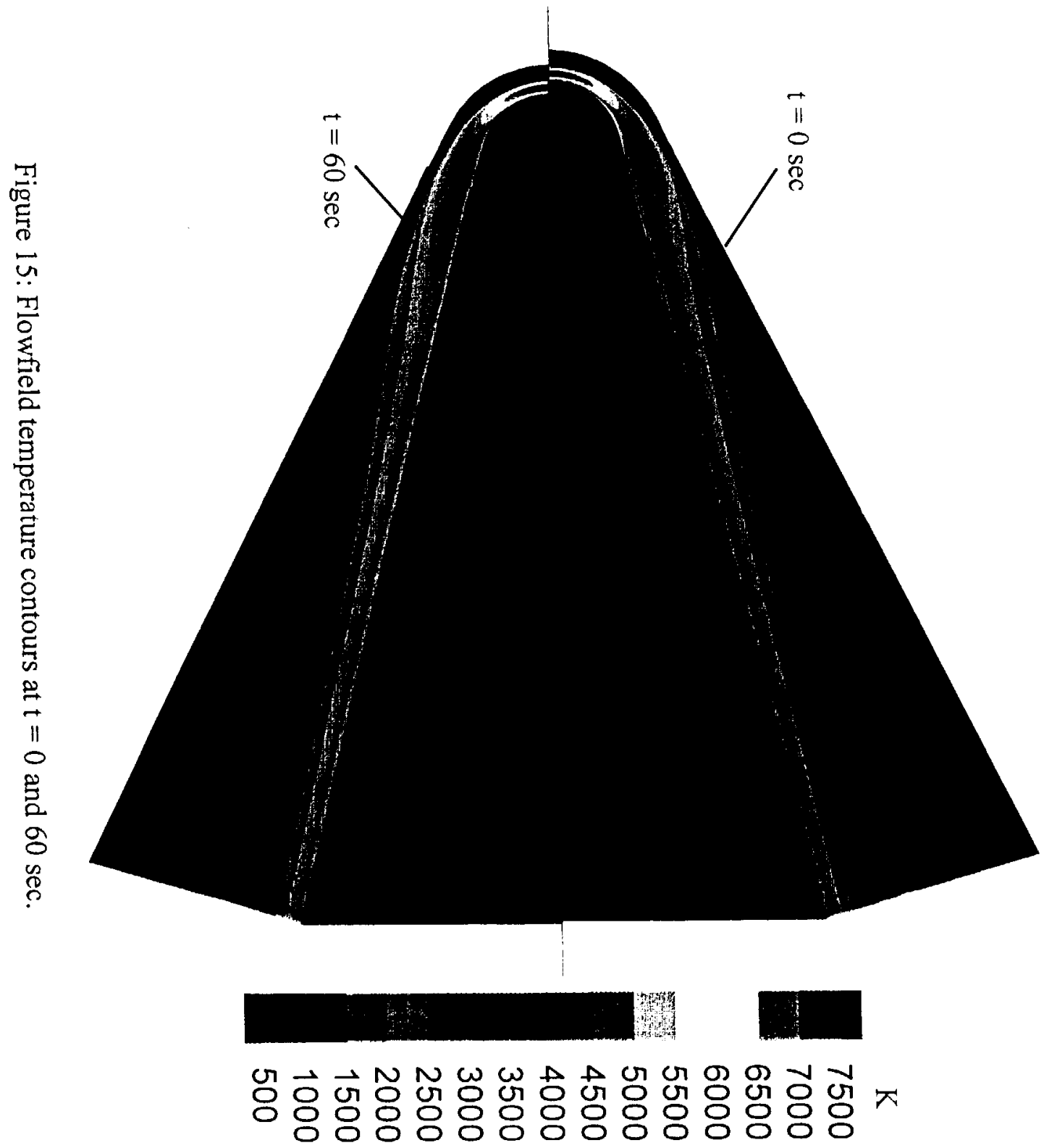

